M.P. Sainov, A.N. Akulinin, D.I. Aleksandrov

М.П. Саинов,

А.Н. Акулинин,

Д.И. Александров

ПРИЧИНЫ

И ПОСЛЕДСТВИЯ АВАРИЙ НА ГИДРОТЕХНИЧЕСКИХ СООРУЖЕНИЯХ ПРУДА У д. НОВОСЁЛКИ

На примере объекта, расположенного у деревни Новосёлки Сергиево-Посадского района Подмосковья, рассмотрены проблемы, возникающие при строительстве малых гидротехнических водоподпорных и водосбросных сооружений. В ходе реконструкции гидротехнических сооружений пруда были допущены серьезные отклонения от проекта, а качество строительных работ оказалось очень низким. Это привело к аварии на водосбросных сооружениях. Во избежание подобных ситуаций необходимо проектировать малые гидротехнические сооружения таким образом, чтобы их конструкции были максимально упрощены и могли выдерживать сверхпроектные условия работы.

Ключевые слова: малые гидротехнические сооружения, авария, водосбросные сооружения, аварии на гидротехнических сооружениях.

\section{ACCIDENT REASONS AND CONSEQUENCES ON HYDROTECHNICAL CONSTRUCTIONS OF THE POND NEAR NOVOSELKI VILLAGE}

In the article some problems that arise during the construction of spillway and backwater structures are considered. As an example we use the object near Novoselki village in Sergiev-Posad district of the Moscow Region. In the process of the hydraulic structures reconstruction the serious deviations from the project were made and the quality of construction works turned out to be very bad. These factors led to the accident on spillway structures. In order to avoid such situations it is necessary to design small hydrotechnical constructions with maximum simplified structures which could withstand overproject work conditions.

The main conclusion is the following: the reliability of the designed structures depends mostly on contracting organizations qualification. The strictures were operating well on the objects where the contracting organization was high-skilled. The structures were built not according to the project and with poor quality on the objects built by unqualified contracting agencies. As a result they were damaged or even destructed. That's why its necessary to choose the constructive decisions that are difficult to "spoil": provide automatic water disposal through waste chute, don't use slope protection made of precast concrete slabs.

Key words: small hydrotechnical structures, accident, spillway structures, accidents on hydrotechnical structures.

До 1970-х гг. в Московской области интенсивно велись торфоразработки. Для добычи торфа производилось осушение торфяников: они с шагом 500 м прорезались сетью дренажных каналов и канав. Из этих каналов вода самотеком собиралась в магистральные каналы, которые отводили воду в близлежащие реки и водоемы. В 1970-х гг. разработка торфа была прекращена, но дренажные сооружения сохранились. Заболачивание торфяников произведено не было. Вследствие этого, в аномально засушливое лето 2010 г. осушенные торфяники стали источниками пожаров. Лишь после этого, была разработана программа по обводнению подмосковных торфяников, расположенных в Егорьевском, Шатурском и СергиевоПосадском районах [1].

Программа обводнения была начата в 2011 г. и завершится в 2013 г.

Обводнение заключается в подъеме уровня грунтовых вод. С этой целью необходимо практически до бровок наполнить водой каналы, которые ранее были осушительными. Подъем уровня воды в каналах достигается с помощью постоянных и временных водоподпорных сооружений. К постоянным сооружениям относятся водопропускные сооружения (ВП), и водопропускные сооружения с затвором (ВПЗ). К временным сооружениям относятся так называемые дамбы перелива.

Студенты МГСУ под руководством участвовали в проектировании гидротехнических сооружений систем обводнения. Необходимо было планировать расчистку обводнительных каналов, конструировать водоподпорные и водопропускные 
сооружения [2]. При этом возник ряд сложностей. Первая проблема - это отсутствие надежных гидрологических прогнозов формирования стока на обводняемых территориях. Вторая - низкое качество строительных работ, проводимых некоторыми подрядными организациями. Эти проблемы можно проиллюстрировать историей ведения работ на одном из объектов, расположенных у д. Новосёлки Сергиево-Посадского района Московской области.

В данном районе на р. Сухмань существует пруд, который образован за счет создания земляной плотины максимальной высотой 4,5 м (рис. 1, 2). Из этого пруда по существующему каналу снабжалась водой система обводнения торфяников у д. Переславичи.

Подъем уровня позволял через водоприемник на левом берегу забирать из пруда воду и по каналу самотеком доставлять воду в верховой магистральный канал торфоразработок у д. Переславичи. Канал к настоящему времени сохранился, а водоприемник (по-видимому, он был кирпичным) - нет.

Помимо этих сооружений были построены лево- и правобережная дамбы, а также водосбросные сооружения. Гребень дамб располагался ниже отметки гребня русловой плотины. Они создавались, чтобы при форсировке уровня пруда исключить возможность движения воды в обход водосбросных сооружений и, следовательно, водной эрозии берегов.

Было построено два водосбросных сооружений. Одно из них находилось в русле и представляло собой башенный трубчатый водосброс (рис. 3). Его глубинное входное отверстие было оборудовано плоским затвором. Водосбросной тракт был выполнен из стальной трубы диаметром около 300 мм. Это водопропускное сооружение, по всей видимости, редко работало как водосброс и служило для спуска воды из пруда в случае необходимости. Территория за ним была заболочена.

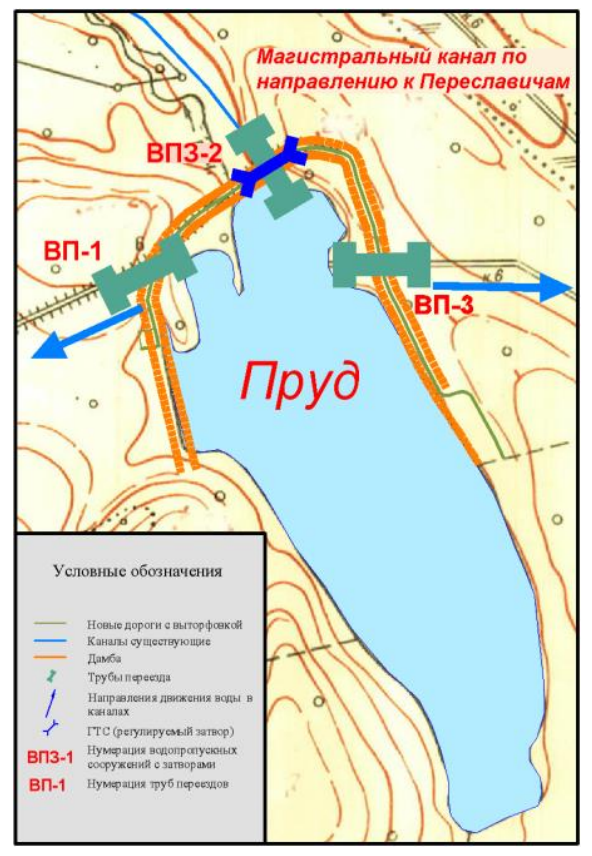

Рис. 1. Генплан сооружений пруда

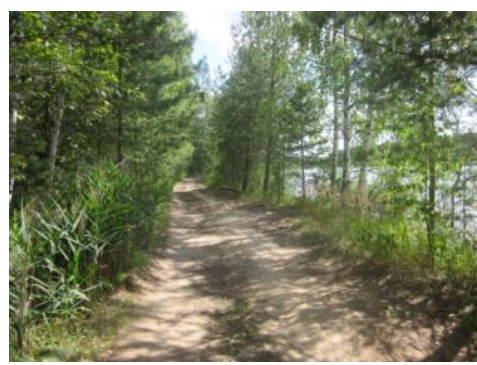

Рис. 2. Гребень русловой плотины до реконструкции

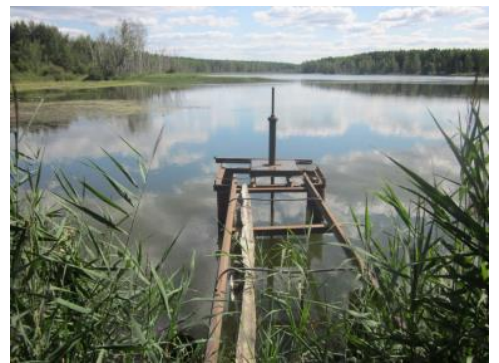

Рис. 3. Башенный водоприемник трубчатого водосброса до реконструкции

Основным водосбросным сооружением являлся правобережный водосброс (рис. 4,5 ). Он представлял собой открытый нерегулируемый канал шириной 8 м. Начальный участок водосброса, покрытый монолитным бетоном, был устроен горизонтальным. Далее он переходил в быстроток, концевая часть которого опиралась на деревянную свайную раму. Гашение энергии свободно падающего потока воды осуществлялось в яме размыва. Правобережный водосброс отводил воду в специально прорытый канал, соединяющийся с р. Сухмань.

Программа обводнения торфяников предусматривала реконструкцию сооружений пруда у д. Новосёлки. При реконструкции было решено оставить принципи- 
альную схему работы водопропускных сооружений пруда без изменений. Однако сами конструкции водосбросных сооружений должны были стать более надежными и удобными. Прежние конструкции были полностью разобраны и заменены новыми.

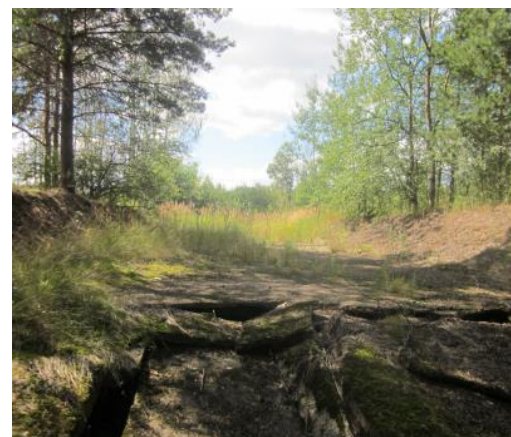

Рис. 4. Канал правобережного водосброса до реконструкции

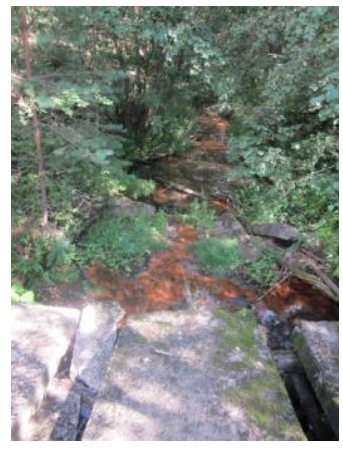

Рис. 5. Концевой участок правобережного водосброса до реконструкции

Русловому водопропускному сооружению было решено придать функции водосброса. При ФПУ 143,67 м его проектная пропускная способность составляет $2,1 \mathrm{~m}^{3} / \mathrm{c}$. В шахте водосброса были устроены поверхностные отверстия, через которые лишняя вода при превышении уровня НПУ могла переливаться в шахту (рис. 6). Металлическая труба была заменена на бетонную большего диаметра. За водосбросом был устроен бетонный водобойный колодец (рис. 7).

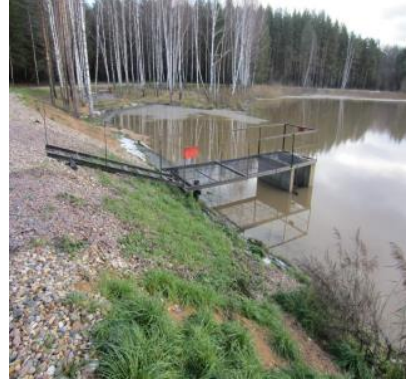

Рис. 6. Водоприемник нового руслового трубчатого водосброса

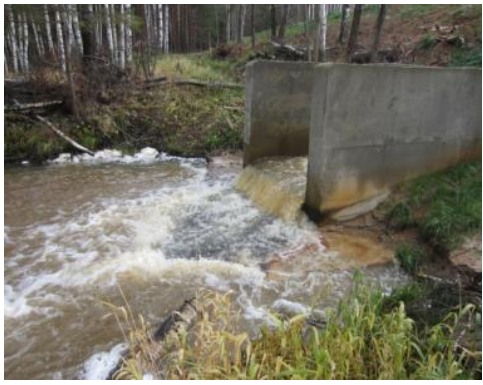

Рис. 7. Водобойный колодец нового руслового трубчатого водосброса

На правобережном водосбросе вместо открытого горизонтального канала были устроены 4 нитки трубопроводов для обеспечения возможности проезда автотранспорта (рис. 7, 8). Быстроток был запроектирован с уклоном. Гашение энергии было предусмотрено гидравлическим прыжком в водобойном колодце.

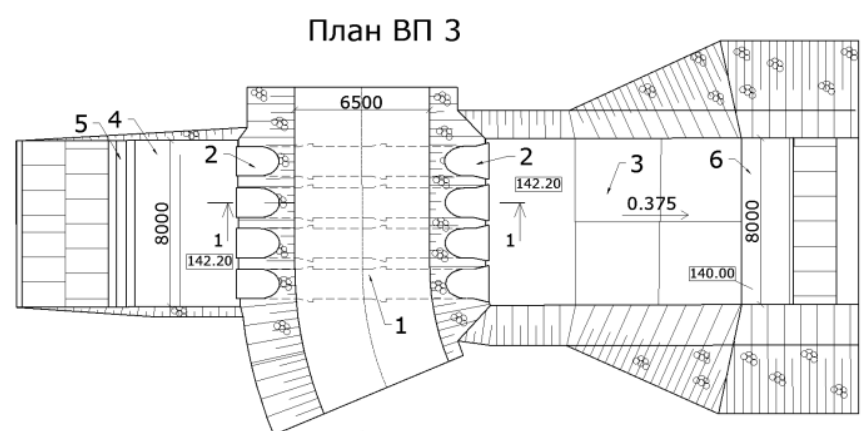

Разрез 1-1

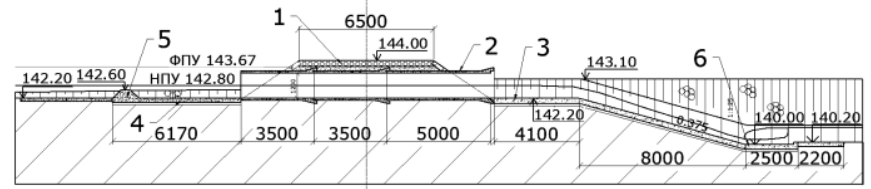

Рис. 7. Конструкция нового правобережного водосброса: 1 - дорожное полотно; гребень дамбы; 2 - бетонный трубчатый водосброс; 3 - крепление канала быстротока; 4 - крепление русла бетоном перед водосбросом; 5 - водосливной порог; 6 - водобойная плита с водобойным колодцем 
Конструкция водозабора системы обводнения была разработана в виде бетонной переливной стенки, которая соединена с боковыми открылками и водобойной плитой в единую монолитную конструкцию (рис. 9). Переливная стенка имела порог на отметке НПУ пруда. За водозабором был запроектирован переезд, в котором вода пропускалась по двум трубам диаметром 1,4 м.

Проектом реконструкции пруда было предусмотрено наращивание дамб и уширение их гребня. Крепление верхового откоса дамб и плотины было запроектировано в виде каменной наброски в георешетке, укладываемой на слой геотекстиля. Для защиты низового откоса от размыва фильтрационным потоком была предусмот-

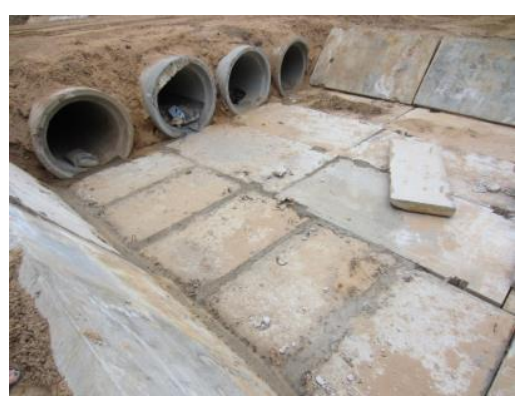

Рис. 8. Новый правобережный водосброс в период строительства рена укладка геотекстиля, пригруженного камнем.

Зимой 2011-2012 гг. велось строительство системы обводнения торфяников у д. Переславичи и реконструкция сооружений пруда у д. Новосёлки. Результаты строительных работ по реконструкции сооружений пруда были неудовлетворительными. Качество работ на земляных сооружениях оказалось слишком низкое:

крепление низового и верхового от-

верховой откос не крепился ниже НПУ; коса часто не выполнялось;

наброска щебня на верховом откосе чаще всего не устраивалась, на геотекстиль вместо камня отсыпался песок;

грунт в теле плотин и дамб не уплотнялся, вследствие чего вблизи откосов образовались трещины и провалы грунта (трещины откола).
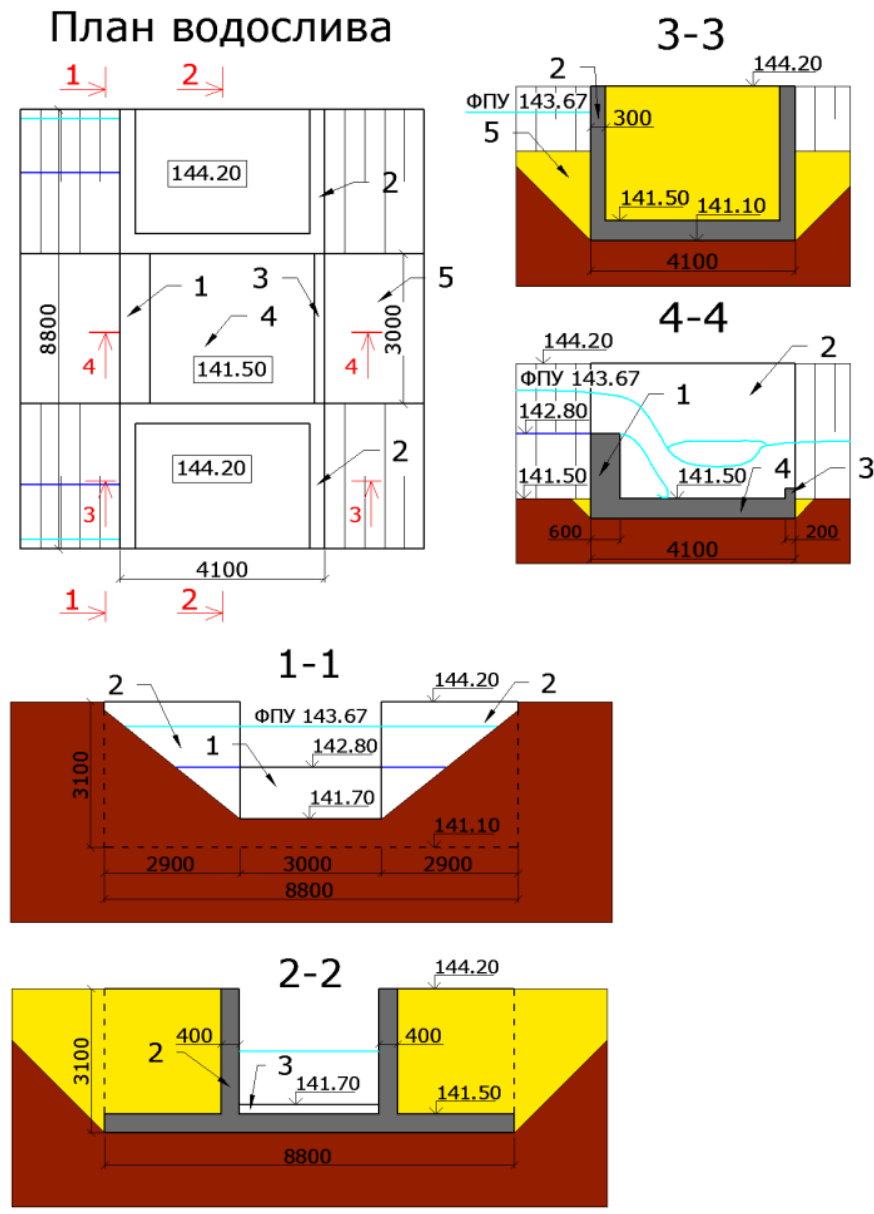

Рис. 9. Конструкция левобережного водозабора после реконструкции: 1 - водосливная стенка; 2 - боковые сопрягающие стенки (устои); 3 - порог водобойного колодца; 4 - водобойная и одновременно фундаментная плита; 5 - рисберма 
Из трех водопропускных сооружений только одно, русловое, было построено почти по проекту (рис. 6,7 ). Оно в настоящий момент функционирует нормально.

Левобережный водозабор был возведен не как цельное сооружение, а как состоящее из трех отдельных элементов: водобойной плиты с переливной стенкой и двух устоев. За водозабором крепление русла устроено не было. Такое сооружение не могло служить водопропускным. При пропуске воды произошел подмыв основания водобойной плиты, устоев, и сооружение «сложилось» (рис. 10).
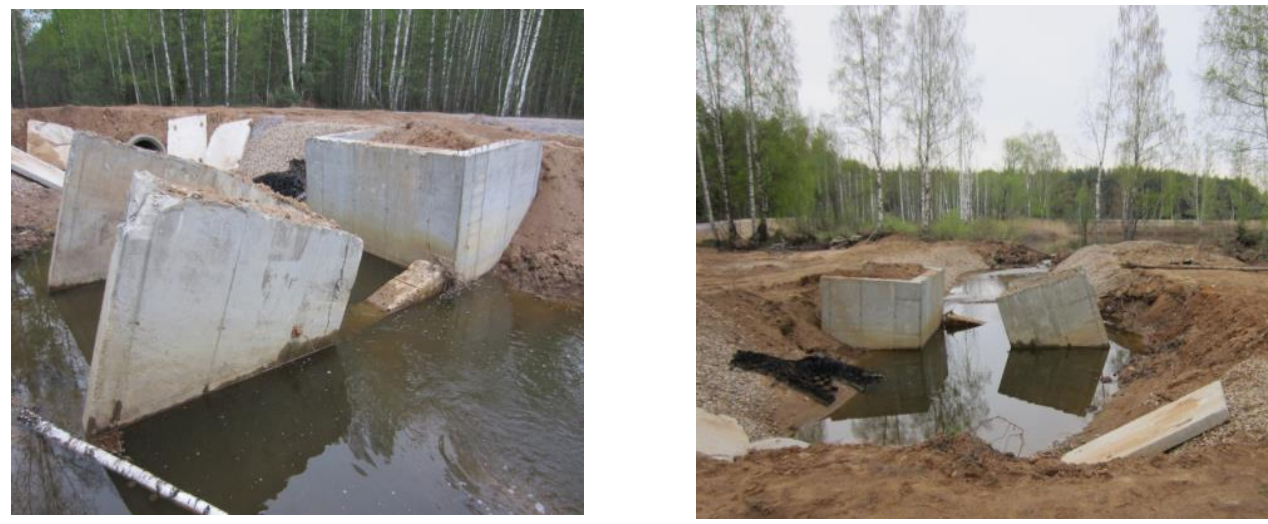

Рис. 10. Водоприемник левобережного водозабора после разрушения

Еще большие проблемы возникли с правобережным водосбросом. Горизонтальный канал и дно труб были устроены примерно на 0,5 м выше проектного. Такое положение резко снизило пропускную способность, водосброс практически не участвовал в пропуске весеннего половодья 2012 г.

Весной 2012 г. в Московской области наблюдался высокий сток половодья (по-видимому, расходы приближались к расчетным 5\%-й обеспеченности). Основной расход половодья пошел через левобережный водозабор. Учитывая, что его конструкция не была приспособлена к пропуску такого расхода, она была разрушена, что значительно увеличило сбрасываемые расходы по сравнению с проектными. Ориентировочно расход воды по каналу составлял от 3 до 8 м $3 / \mathrm{c}$.

По магистральному каналу воды половодья поступили в обводнительную систему у д. Переславичи. Построенные там сооружения не были рассчитаны на пропуск столь значительных расходов. Кроме того, они тоже были созданы не по проекту, с грубыми нарушениями. Особо важным является то, что сороудерживающая решетка была устроена не вровень с водосливным порогом шахты (как по проекту), а над ним. Это привело к ограничению пропускной способности ВП и ВПЗ. В результате произошла сверхпроектная форсировка уровня воды в каналах. Вода достигла гребня земляных дамб, а затем перелилась через них. Все дамбы ВП и ВПЗ были размыты. В них образовался проран почти с вертикальными откосами (рис. 11). Дамбы перелива также были размыты со стороны более низкого берега потоком, когда он двигался в обход сооружения.

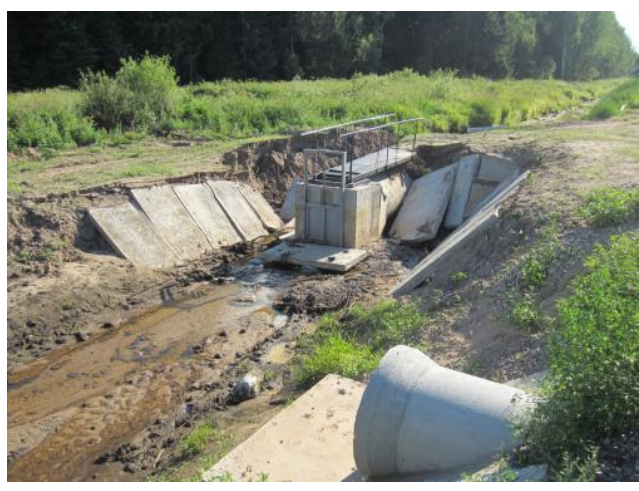

Рис. 11. Разрушенное водопропускное

Все сооружения системы об- сооружение с затвором (ВПЗ) воднения были разрушены.

За лето 2012 г. сооружения были восстановлены и даже модернизированы. Бетонный левобережный водозабор пруда был омоноличен за счет устройства бетонного массива на водобойной плите (рис. 12). Русло за ним было укреплено.

На дамбах растительность на верховом и низовом откосе проросла сквозь геотекстиль и создана естественное биологическое крепление (рис. 13). 

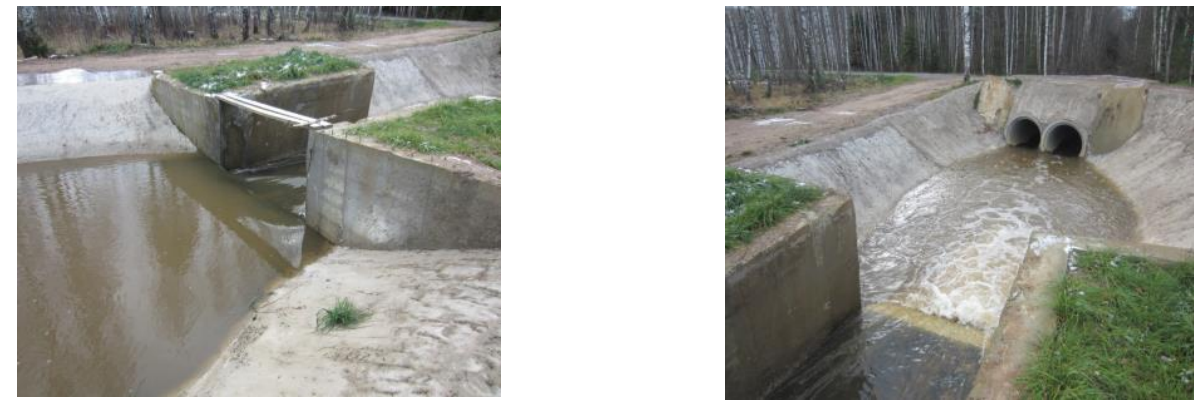

Рис. 12. Левобережный водозабор после восстановления

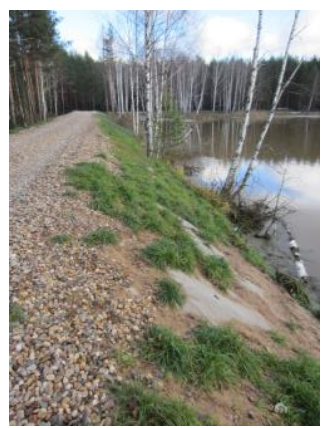

Рис. 13. Фото русловой плотины после реконструкции

Но на этом злоключения данного объекта не закончились. В октябре 2012 г. на реках Подмосковья наблюдались повышенные паводковые расходы. Не стала исключением и р. Сухмань. Но на сей раз левобережный канал не смог пропускать большие расходы, так как водозабор был восстановлен. В паводок уровень воды в пруде поднялся выше порога правобережного водосброса. Его реализованная строителями конструкция оказалась ненадежной. И он был полностью размыт за исключением входного участка (рис. 14).
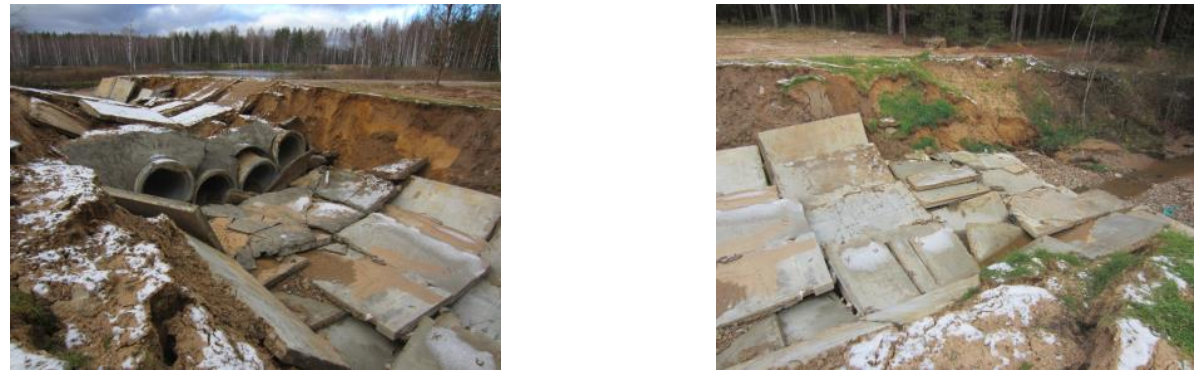

Рис. 14. Фото разрушенного правобережного водосброса

Это объясняется следующими причинами:

1) монолитная водобойная плита в конце быстротока была заменена на ряд отдельных сборных плит, при этом плиты были уложены не на всю проектную длину (рис. 15). Плиты укладывались на гравийно-песчаную подготовку.

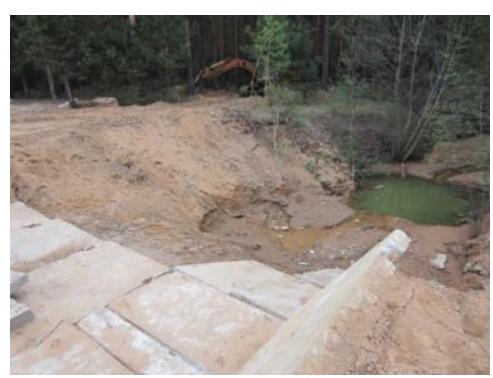

Рис. 15. Состояние крепления за правобережным водосбросом в процессе строительства
По-видимому, под ними оставались пустоты. Крепление из сборных плит не могло выдержать гидродинамических нагрузок, швы между ними раскрылись и водный поток смог их подмывать.

2) в результате ошибки строителей порог правобережного быстротока устроили на 0,5 м выше проектного уровня. Плиты крепления быстротока, по-видимому, оказались неустойчивыми на откосе.

В конце осени 2012 г. правобережный водосброс стоял в руинах. Зимой 2013 г. он был полностью разобран, а затем создан заново.

Таким образом, в результате ошибок строителей на гидротехнической системе обводнения торфяников у д. Переславичи и гидротехнических сооружениях пруда у д. Новосёлки в Московской области произошел ряд аварий сооружений, сопровождавшимися гидродинамическими авариями. В настоящее время опасная ситуация сохраняется. 
При проектировании малых гидротехнических сооружений следует применять наиболее простые конструкции и учитывать низкий уровень качества строительных работ у возможных подрядчиков. В частности следует избегать применения сборных плит для крепления русла за водопропускными сооружениями.

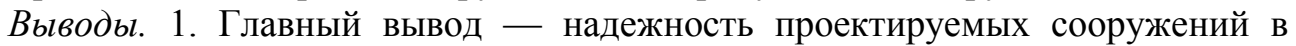
большей степени зависит от квалификации подрядных организаций. На объектах, где подрядная организация обладала достаточным опытом работы, сооружения функционировали надежно. На объектах, построенных неквалифицированными подрядчиками, сооружения возводились не по проекту и некачественно, вследствие чего они повреждались или даже разрушались. Поэтому при проектировании малых гидротехнических сооружений необходимо выбирать такие конструктивные решения, которые трудно «испортить»:

предусматривать автоматический сброс воды через водосбросы,

отказываться от использования крепления откоса из сборных железобетонных плит.

2. Проектирование системы обводнения нужно вести с учетом возможности высокой вероятности возникновения гидродинамических аварий на смежных сооружениях. Гидрологические прогнозы для таких систем не достаточно точны, а сами сооружения изначально не достаточно надежны, поэтому разрушение одного из сооружений системы вполне вероятно. Чтобы в результате аварийного подъема уровня воды в системе не были размыты остальные сооружения, необходимо предусматривать возможность осуществления транзитного пропуска воды по системе со сбросом за пределы системы. В связи с этим проектная пропускная способность водопропускных сооружений должна быть больше предусмотренной нормами.

\section{БИБЛИОГРАФИЧЕСКИЙ СПИСОК}

1. Маршев С.В. Обводнение территории торфяных болот в Московской области // Территория и планирование. 2011. № 4(34). С. 44-53.

2. Саинов М.П., Акулинин А.Н. Опыт проектирования малых гидротехнических сооружений для систем обводнения торфяников // Интеграция, партнерство и инновации в строительной науке и образовании : сб. ст. М. : МГСУ, 2012. С. 494-498.

\section{REFERENCES}

1. Marshev S.V. Obvodnenie territorii torfyanykh bolot v Moskovskoy oblasti [Irrigation of Peatbog Territories in Moscow Region]. Territoriya i planirovanie [Territories and Planning], 2011, no. 4(34), pp. 44-53.

2. Sainov M.P., Akulinin A.N. Opyt proektirovaniya malykh gidrotekhnicheskikh sooruzheniy dlya sistem obvodneniya torfyanikov [Design Experience of Small Hydraulic Engineering Structures for the Peatbog Irrigation Systems]. Integratsiya, partnerstvo i innovatsii v stroitel'noy nauke i obrazovanii: sbornik statey [Integration, Partnership and Innovations in Construction Industry and Education: Collection of Works]. Moscow, MGSU Publ., 2012, pp. 494—498.

Поступила в редакцию в октябре 2013 г.

Об авторах: Саинов Михаил Петрович кандидат технических наук, доцент, доцент кафедры гидротехнических сооружений, ФГБОУ ВПО «Московский государственный строительный университет» (ФГБОУ ВПО «МГСУ»), 129337, г. Москва, Ярославское шоссе, д. 26, mp_sainov@ mail.ru;

Акулинин Антон Николаевич студент Института гидротехнического и энергетического строительства, ФГБОУ ВПО «Московский государственный строительный университет» (ФГБОУ ВПО «МГСУ»), 129337, г. Москва, Ярославское шоссе, д. 26, saleric@bk.ru;

Александров Даниил Ильич - студент Института гидротехнического и энер-
About the authors: Sainov Mikhail Petrovich - Candidate of Technical Sciences, Assistant Professor, Department of Hydrotechnical Structures, Moscow State University of Civil Engineering (MGSU), 26 Jaroslavskoe shosse, Moscow, 129337, Russian Federation; mp_sainov@mail.ru;

Akulinin Anton Nikolaevich — student, Institute of Hydrotechnical and Energetic Construction, Moscow State University of Civil Engineering (MGSU), 26 Jaroslavskoe shosse, Moscow, 129337, Russian Federation; saleric@bk.ru;

Aleksandrov Daniil Il'ich - student, Institute of Hydrotechnical and Energetic Construction, Moscow State University of Civil 
гетического строительства, ФГБОУ ВПО «Московский государственный строи- Moscow, 129337, Russian Federation; тельный университет» (ФГБОУ ВПО 1danon1@gmail.com «МГСУ»), 129337, г. Москва, Ярославское шоссе, д. 26, 1danon1 @ gmail.com.

Для цитирования:

Саинов М.П., Акулин А.Н., Александров Д.И. Причины и последствия аварий на гидротехнических сооружениях пруда у д. Новосёлки [Электронный ресурс] // Строительство: наука и образование. 2013. Вып. 3. Ст. 1 . Режим доступа: http://www.nso-journal.ru.

For citation:

Sainov M.P., Akulin A.N., Aleksandrov D.I. Prichiny i posledstviya avariy na gidrotekhnicheskikh sooruzheniyakh pruda u d. Novoselki [Accident Reasons and Copnsequences on Hydrotechnical Constructions of the Pond near Novoselki Village]. Stroitel'stvo: nauka i obrazovanie [Construction: Science and Education]. 2013. no. 3, paper 1. Available at: http://www.nso-journal.ru. 